\title{
Antioxidant potentials and quality aspects of Jamun (Syzygium cumini L.) supplemented unleavened flat bread (Indian chapatti)
}

\author{
Swati Kapoor ${ }^{*}$, Pushpinder Singh Ranote and Savita Sharma \\ Department of Food Science and Technology, Punjab Agricultural University, Ludhiana-141004 (Punjab), INDIA \\ ${ }^{*}$ Corresponding author. E-mail: swatikapoor74@yahoo.com
}

Received: November 19, 2014; Revised received: March 25, 2015; Accepted: April 22, 2015

Abstract: Enriched chapattis prepared by supplementing whole wheat flour with Jamun (Syzygium cumini L.) pulp at 5,10 and $15 \%$ were assessed for antioxidant activity and quality. Jamun pulp supplementation enhanced the bioactive composition of chapatti in terms of increased anthocyanins, total phenols and antioxidant activity. Total phenolic content and antioxidant activity increased $99.73 \%$ and $44.38 \%$, respectively after incorporation of Jamun pulp (15\%) to whole wheat flour Indian chapatti. Anthocyanins were not observed in control chapatti and in Jamun supplemented chapatti the range was 1.41-2.64 mg/100g content for 5-15\% supplementation level. Qualitative evaluation revealed non-sticky behavior of dough supplemented with Jamun at 5 and $10 \%$ level and slight stickiness at $15 \%$ level. Chapattis exhibited full puffing at all supplementation levels. Sensory scores were highest for $10 \%$ Jamun supplemented chapatti. Crude fiber content improved significantly (13.77\% increase) in chapattis on supplementation of Jamun pulp. The study concluded that supplementation of wheat flour with Jamun pulp improved nutritional and antioxidant status of chapatti.

Keywords: Antioxidant activity, Chapatti, Colour, Jamun (Syzygium cumini L.), Texture

\section{INTRODUCTION}

Jamun (Syzygium cumini L.) known as Indian blackberry has long been used as a traditional medicine to cure various lifestyle diseases such as diabetes, cardiovascular diseases, age related macular degeneration and others (D’Mello et al., 2000; Sagrawat et al., 2006). Use of fruits and vegetables as an ingredient in processed food products is garnering attention worldwide due to rise in importance of the concept of "phytochemicals" as they have the ability to combat and prevent the development of deadly diseases such as cancer and cardiovascular diseases. Jamun fruits are rich in vitamins, minerals and carbohydrates (Sharma et al., 2012). The main phytochemicals found in Jamun fruit are anthocyanins, tannins and other phenolic compounds. Anthocyanins have shown antagonistic activity to some bacteria, virus and fungi and also protect food from microbial spoilage (Chattopadhyay et al., 2008). Chapatti along with other bakery products can be used as a cost-effective carrier of phytochemicals derived from fruits and vegetables. The upcoming trends in the food industry focus on the theme of health and wellness, thus, food scientists are exploring the opportunities to combine various food sources and develop a wholesome healthy product. Incorporation of real fruit in cereal products creates excellent opportunities for new product development and among this chapatti represents one of the routinely consumed cereal product in Indian diet.

Jamun fruit has been processed in various ways such as jams, jellies, squash, vinegar, wine in order to preserve and relish it round the year as it is seasonal in nature being very short duration crop. The era of amalgamation of cereal-fruits and vegetable is rising in view to enhance the antioxidant status of cereal based products. Cereal products are high in protein content compared to fruits and vegetables whereas fruits and vegetables are high in bioactive compounds such as carotenoids, ascorbic acid and phenolic acids (anthocyanins, tannins). Therefore, combination of the two can serve the dual purpose in a diet making the diet rich in proteins as well as phytochemicals in the finished product (Francis and Phelps, 2003).

Chapatti, unleavened flat bread is one of the staple diets of Indian people and about $85 \%$ of wheat in India is consumed in the form of chapattis (Kadam et al., 2012). Incorporation of processed Jamun pulp in the whole wheat flour can help improve the nutritional status of masses by increasing the antioxidant status of the chapatti. Therefore, the present investigation has been done to study the utilization of processed Jamun (Syzygium cumini L.) pulp in whole wheat flour and to assess the antioxidant, qualitative and physico-chemical properties of Jamun pulp supplemented Indian chapattis.

\section{MATERIALS AND METHODS}

Raw materials: Jamun (S. cumini L.) fruit and whole wheat flour was obtained from local market, Ludhiana, Punjab, India.

Processing of Jamun fruit into pulp: Jamun fruit was 
processed into pulp by heating gently for $10 \mathrm{~min}$. at $60^{\circ} \mathrm{C}$ in its own juice. Seeds were removed manually and pulp was collected by passing the seedless material through fruit strainer. Pulp was further heated to $82^{\circ} \mathrm{C}$ for $3 \mathrm{~min}$., filled hot in pre-sterilized clean glass bottles $(200 \mathrm{ml})$ and processed in boiling water for $20 \mathrm{~min}$. and then cooled to room temperature. The bottles were stored at $4-7^{\circ} \mathrm{C}$ till further use.

Chapatti preparation: Unleavened flat bread or chapatti was prepared following the procedure described by Austin and Ram (1971). Processed Jamun pulp was blended with the whole wheat flour $(50 \mathrm{~g})$ at the levels of 5, 10 and $15 \%$ and mixed with desired quantity of water. The water required to form viscoelastic dough was reported as water absorption (\%). Manual kneading was done for 2.5 minutes for dough development and dough was rested for $30 \mathrm{~min}$. at $30^{\circ} \mathrm{C}$ and $85 \% \mathrm{RH}$ (relative humidity). Dough was divided into four equal parts and rounded manually followed by sheeting/ rolling on smooth surface to obtain circular chapattis of $15 \mathrm{~cm}$ in diameter. The raw chapatti was immediately placed on an open hot girdle and baked on one side and then inverted and baked on the other side followed by final baking on the first side. Final product was optimized on the basis of quality (puffiness and stickiness) and sensory evaluation score for different attributes.

Quality evaluation of chapatti: Comparative evaluation of cooled chapattis was done by observing stickiness, puffing and sensory quality (Dar et al., 2014). Dough handling characteristics such as non-sticky, sticky, slightly sticky and very sticky parameters along with puffing characteristics of chapatti such as full, partial and nil were observed during chapatti making.

Sensory evaluation: Jamun supplemented chapattis were evaluated for sensory attributes (appearance, colour, flavour, texture and overall acceptability) using 9- point hedonic scale (Larmond, 1970). Seven semi-trained panellists in the age group of 22-55 years having no medical disorder from the Department of Food Science and Technology, Punjab Agricultural University, Ludhiana were selected to evaluate the sensory properties of chapattis.

Colour analysis: Colour analysis was performed using Hunter Lab Colorimeter, MiniScan XE Plus (Hunter Lab, Reston, VA). Colour readings were expressed by Hunter values for $L^{*}, a^{*}$ and $b^{*}$. The a* value ranges from -100 (greenness) to +100 (redness), the $b^{*}$ value ranges from -100 (blueness) to +100 (yellowness), whereas the $L^{*}$ value, indicating the measure of lightness, ranges from 0 (black) to 100 (white) (Hutchings, 1999). Hue angle was calculated using the formula $\tan ^{-1} b^{*} / a^{*}$.

Texture analysis: The texture of chapatti was analyzed using Texture Analyzer (Stable Micro Systems, Model TA-HDi, UK). Strips measuring $4 \mathrm{~cm} \times 2 \mathrm{~cm}$ were cut from each chapatti. One strip at a time was placed on the centre of the sample holder and the Warner wratzler blade was allowed to cut the chapatti strip.
The force $(\mathrm{N})$ required to cut chapatti strip into two pieces was recorded. The speed was maintained at 1.70 $\mathrm{mm} / \mathrm{s}$ (Dar et al., 2014).

Proximate composition: Fresh Jamun fruit and processed Jamun pulp was evaluated for total solids and ash (AOAC, 2000). Total sugars and reducing sugars were estimated using Lane and Eynon method (AOAC, 2000). Crude fibre of prepared chapattis was estimated using Fibertec (FOSS) (AACC, 2000).

Bioactive composition: Ascorbic acid has been determined using direct colorimetric method (Ranganna, 1997) and expressed as $\mathrm{mg} / 100 \mathrm{~g}$. The samples were analyzed for total anthocyanins content by spectrophotometric method (Srivastava and Kumar, 1994) and expressed as $\mathrm{mg} / 100 \mathrm{~g}$. Total phenolic content was determined according to Folin-Ciocalteu spectrophotometric method (Gao et al., 2002). Sample (5 g) was mixed with $80 \%$ methanol $(50 \mathrm{ml})$ and refluxed for 2 hours. Aliquot was $(0.2 \mathrm{ml})$ was added to $0.8 \mathrm{ml}$ of distilled water. Thereafter, $5 \mathrm{ml}$ of fresh Folin- Ciocalteu reagent (10 fold dilution) was added and the mixture was allowed to equilibrate for 8 minutes followed by addition of $4 \mathrm{ml}$ saturated sodium carbonate solution. The mixture was incubated in dark at room temperature for 60 minutes, the absorbance of the mixture was then observed at $765 \mathrm{~nm}$ (Spectronic 20, Bausch \& Lomb, USA). The results were expressed as $\mathrm{mg} \mathrm{GAE} / 100 \mathrm{~g}$ by taking gallic acid as reference material to construct standard curve.

Antioxidant activity: Antioxidant activity was determined by $\operatorname{DPPH}(2,2$ di phenyl picryl hydrazyl) method according to Brand-Williams et al. (1995) with some modifications. Briefly, samples (5 g) were extracted with $80 \%$ methanol for $2 \mathrm{hrs}$ and filtered; aliquot collected and made volume to $100 \mathrm{ml}$ with $80 \%$ methanol. The assay contained $2 \mathrm{ml}$ of sample aliquot, $2 \mathrm{ml}$ of tris $\mathrm{HCl}$ buffer ( $\mathrm{pH} \mathrm{7.4)}$ and $4 \mathrm{ml}$ of $0.1 \mathrm{mM}$ DPPH. The contents were mixed immediately and the degree of reduction of absorbance was recorded continuously for 30 min. at $517 \mathrm{~nm}$ (Spectronic 20, Bausch \& Lomb, USA). Antioxidant activity was calculated according to following formula.

Antioxidant activity $(\%)=$ Control Absorbance $(0 \mathrm{~min})$ - Sample Absorbance $(30 \mathrm{~min}) \times 100 /$ Control Absorbance (0 min)

Statistical analysis : The results were expressed as mean \pm standard deviation (SD) $(n=3)$. Data were analyzed by student's t-test for fresh and processed Jamun pulp and data collected from Jamun pulp supplemented chapattis were subjected to variance (ANOVA) analysis and their comparison were done through Duncan's multiple range test with $\mathrm{p} \leq 0.05$ significance level on SPSS 18.0 statistical software (SPSS Inc.).

\section{RESULTS AND DISCUSSION}

Bioactive composition of fresh Jamun and processed Jamun pulp: The bioactive composition of fresh Jamun and processed Jamun pulp are given in table 1 . 
The results revealed ascorbic acid content 21.77 $\mathrm{mg} / 100 \mathrm{~g}$ for fresh Jamun and $18.29 \mathrm{mg} / 100 \mathrm{~g}$ for processed Jamun pulp. Ascorbic acid is a reducing agent and is vulnerable to light induced oxidation in addition to thermal degradation that may have occurred during processing of Jamun pulp. The anthocyanin content of fresh Jamun and processed Jamun pulp was found as $126.54 \mathrm{mg} / 100 \mathrm{~g}$ and $112.56 \mathrm{mg} / 100 \mathrm{~g}$ (Table 1). Chowdhury and Ray (2007) depicted $140 \mathrm{mg} / 100 \mathrm{~g}$ anthocyanins in Jamun fruit. Temperature is one of the factors that affect the stability of anthocyanins and degradation of anthocyanins occurs with increase in temperatures (Kopjar et al., 2009). Total phenolic content of processed Jamun pulp was noted to be slightly lower than fresh fruit (Table 1). Fresh Jamun had $91.83 \%$ antioxidant activity and processed Jamun pulp was found to have $88.68 \%$ antioxidant activity. The results of our study corroborates with Ali et al. (2013) who reported $85.22 \%$ of free radical scavenging capacity in Jamun pulp. Processing altered the antioxidant activity of fresh Jamun which may be due to degradation of ascorbic acid, anthocyanins and phenolic compounds on processing.

Physico-chemical composition of fresh Jamun and processed Jamun pulp: Physico-chemical composition of fresh Jamun and processed Jamun pulp is depicted in fig. 1. Total soluble solids for fresh Jamun fruit was $10.2^{\circ} \mathrm{B}$ and for processed Jamun pulp it was $11.9{ }^{\circ} \mathrm{B}$.
Total solids of fresh and processed Jamun pulp that comprised mainly of reducing and total sugars, acids, crude fibre, protein and ash were found to be $12.62 \%$ and $13.37 \%$, respectively. Increased total solids of processed Jamun pulp compared to fresh Jamun fruit may be due to concentration of pulp during processing. Total sugar values correspond to $16.92 \%$ and $15.33 \%$, respectively for fresh Jamun and processed Jamun pulp. The results are in line with Joshi et al. (2012) who reported $12.44 \%$ of total sugars in Jamun fruit. Crude fiber and ash content of fresh Jamun was found to be $0.86 \%$ and $0.32 \%$, respectively. Similarly, for processed pulp it was $0.64 \%$ and $0.27 \%$, respectively. An appropriate amount of crude protein content in fresh Jamun fruit and processed Jamun pulp was observed as 0.87 and $0.84 \%$, respectively. Shahnawaz et al. (2009) reported slightly lower values of protein $(0.72 \%)$ for freshly extracted Jamun pulp. The difference may be due to different cultivars.

Quality assessment: Qualitative characteristics of chapatti supplemented with Jamun pulp at 5, 10 and $15 \%$ levels have been tabulated in table 2 . Statistically significant $(p \leq 0.05)$ variation was observed for water absorption of unsupplemented and supplemented whole wheat flour. Water absorption of control whole wheat flour for dough making was $66.29 \%$. Less water was required for dough development with increase in supplementation level of pulp from 5 to $15 \%$.

Dough handling characteristics of Jamun pulp supplemented

Table 1. Bioactive composition of fresh Jamun and processed Jamun pulp.

\begin{tabular}{lcccc}
\hline Parameters & $\begin{array}{c}\text { Ascorbic acid } \\
(\mathbf{m g} / \mathbf{1 0 0 g})\end{array}$ & $\begin{array}{c}\text { Anthocyanin } \\
(\mathbf{m g} / \mathbf{1 0 0 g})\end{array}$ & $\begin{array}{c}\text { Total phenols (mg } \\
\text { GAE/100g) }\end{array}$ & $\begin{array}{c}\text { Antioxidant activity } \\
(\mathbf{\%})\end{array}$ \\
\hline Jamun fruit & $21.77^{\mathrm{a}} \pm 0.25$ & $126.54^{\mathrm{a}} \pm 0.67$ & $2250.91^{\mathrm{a}} \pm 0.55$ & $91.83^{\mathrm{a}} \pm 0.57$ \\
Processed Jamun pulp & $18.29^{\mathrm{b}} \pm 0.36$ & $112.56^{\mathrm{b}} \pm 0.62$ & $2158.89^{\mathrm{b}} \pm 0.64$ & $88.68^{\mathrm{b}} \pm 0.51$ \\
\hline
\end{tabular}

GAE: Gallic acid equivalent; means with different letters in the same column are significantly different $(\mathrm{p} \leq 0.05)$.

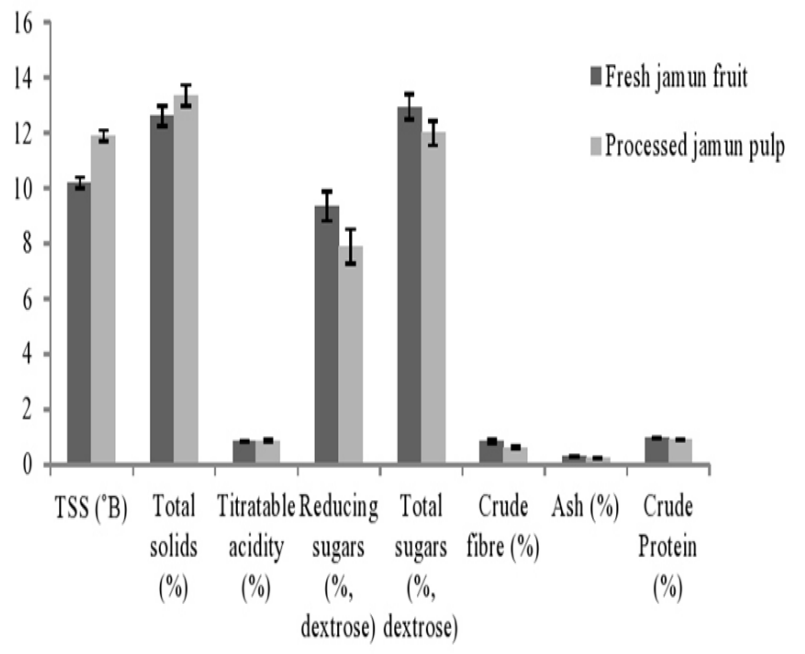

Fig.1. Physico-chemical composition of fresh Jamun fruit and processed Jamun pulp. chapatti did not show significant variation, however, dough at $15 \%$ supplementation level showed slightly sticky behaviour than control, 5 and 10\% supplementation level. Puffing is one of the most desired quality characteristics of chapatti and influences the consumer acceptability. Control and supplemented chapattis exhibited full puffing. Significant $(\mathrm{p} \leq 0.05)$ differences were established among the appearance, colour, flavour and overall acceptability scores that are listed in Table 2 whereas, non-significant effect of different supplementation levels on texture was observed. Sensory evaluation studies reported highest overall acceptability scores for $10 \%$ Jamun pulp supplemented chapatti mainly on the basis of appearance and flavour. Jamun supplemented chapattis at 5 and $15 \%$ were also highly acceptable.

Colour and texture analysis: The colour and texture values of Jamun supplemented chapattis have been elucidated in table 3 . Statistically significant $(\mathrm{p} \leq 0.05)$ difference was observed in $L^{*}$ (Lightness) value of 
Jamun supplemented chapattis. L* value lowered with increasing supplementation levels resulting in darker chapattis. $\mathrm{L}^{*}$ values of control chapatti was found to be 74.76 and for 5,10 and $15 \%$ supplementation level it was found to be $70.79,68.95$ and 67.45 , respectively leading to decreased brightness with increasing supplementation levels. The data in Table 3 depicts that $a^{*}$ (Redness) value increased with increase in Jamun supplementation level in chapatti. The $\mathrm{b}^{*}$ (Blueness) value reduced gradually from 16.14 at $0 \%$ supplementation level to 14.25 at $15 \%$ supplementation level with increasing supplementation level indicating an increase in blueness of supplemented samples that might be due to increase in anthocyanin content in increasing supplementation levels of Jamun pulp. The results are in agreement with the study of Camire et al. (2007) where the authors reported lowest $L^{*}$ and $b^{*}$ values (darker and more blue) in breakfast cereal supplemented with blueberry fruit powder and highest $a^{*}$ value in red raspberry powder incorporated breakfast cereal indicating positive correlation between anthocyanin content and $\mathrm{a}^{*}$ values and negative correlation between anthocyanins and $\mathrm{L}^{*}, \mathrm{~b}^{*}$ values. Similarly hue angle reduced with increasing supplementation levels from 80.11 at $0 \%$ supplementation level to 71.60 at $15 \%$ supplementation level. Total anthocyanins were found to have correlation with $\mathrm{L}^{*}\left(\mathrm{r}^{2}=-0.83\right), \mathrm{a}^{*}\left(\mathrm{r}^{2}=0.63\right)$ and hue angle $\left(\mathrm{r}^{2}=-0.74\right)$ as lower anthocyanin content resulted in lower degree of redness and higher $\mathrm{L}^{*}$ and colour hue values (Cliff et al., 2007) in different varieties of red wine.

Textural studies of chapattis signify texture of the chapattis and it stimulates the biting action of the human teeth on chapattis (Sidhu et al., 1988). Significant ( $p>0.05$ ) effect of Jamun pulp supplementation levels on cutting force of chapattis was found (Table 3). Minimum cutting force was required for $15 \%$ Jamun pulp supplemented chapatti $(0.25 \mathrm{~kg})$ and maximum was required for control chapatti $(0.31 \mathrm{~kg})$ depicting increase in softness of chapattis with increasing supplementation levels. Cutting force of 5\% and 10\% Jamun pulp supplemented chapatti was found to be 0.29 and $0.27 \mathrm{~kg}$, respectively.

Bioactive and physico-chemical composition of Jamun supplemented chapatti

Physico-chemical composition: Physico-chemical composition of Jamun pulp supplemented chapatti is depicted in Table 4. Supplemented chapatti at 5\% level did not differ significantly $(\mathrm{p}>0.05)$ from control for moisture content but at $10 \%$ level significant $(\mathrm{p} \leq 0.05)$ effect was found. Moisture content of chapatti was $34.99 \%$ at $0 \%$ supplementation levels and in the range of $35.07-35.55 \%$ at $5-15 \%$ level. The increase in moisture content may be due to presence of fruit fibres in Jamun pulp, as these fibres are reported to contain more pectin and have a higher water binding capacity than those of the cereal and legume fibres (Chen et al., 1984). Protein content did not differ much with 
Table 3. Colour and texture ( $\mathrm{kg})$ of Jamun supplemented Indian chapatti.

\begin{tabular}{cccccc}
\hline Supplementation level & Lightness $\left(\mathbf{L}^{*}\right)$ & Redness $\left(\mathbf{a}^{*}\right)$ & Blueness $\left(\mathbf{b}^{*}\right)$ & Hue angle $\left(^{\circ}\right.$ ) & Cutting force $^{\text {Cun }}$ \\
\hline Control & $74.76^{\mathrm{a}} \pm 0.72$ & $2.81^{\mathrm{b}} \pm 0.30$ & $16.14^{\mathrm{a}} \pm 0.28$ & $80.11^{\mathrm{a}} \pm 1.21$ & $0.31^{\mathrm{a}} \pm 0.01$ \\
$5 \%$ & $70.79^{\mathrm{b}} \pm 0.76$ & $4.38^{\mathrm{a}} \pm 0.37$ & $16.01^{\mathrm{a}} \pm 0.22$ & $74.69^{\mathrm{b}} \pm 1.43$ & $0.29^{\mathrm{ab}} \pm 0.00$ \\
$10 \%$ & $68.95^{\mathrm{c}} \pm 0.82$ & $4.61^{\mathrm{a}} \pm 0.26$ & $15.05^{\mathrm{b}} \pm 0.18$ & $72.97^{\mathrm{bc}} \pm 0.71$ & $0.27^{\mathrm{bc}} \pm 0.01$ \\
$15 \%$ & $67.45^{\mathrm{d}} \pm 0.63$ & $4.74^{\mathrm{a}} \pm 0.28$ & $14.25^{\mathrm{c}} \pm 0.25$ & $71.60^{\mathrm{c}} \pm 0.71$ & $0.25^{\mathrm{c}} \pm 0.01$ \\
\hline
\end{tabular}

Means with different letters in the same column are significantly different $(\mathrm{p} \leq 0.05)$.

Table 4. Physico-chemical characteristics of Jamun supplemented Indian chapatti.

\begin{tabular}{cccccc}
\hline Supplementation (\%) & Moisture (\%) & Protein (\%) & Ash (\%) & Crude fibre (\%) & Fat (\%) \\
\hline Control & $34.99^{\mathrm{c}} \pm 0.10$ & $11.98^{\mathrm{a}} \pm 0.09$ & $1.45^{\mathrm{a}} \pm 0.03$ & $1.67^{\mathrm{c}} \pm 0.02$ & $1.30^{\mathrm{a}} \pm 0.03$ \\
5 & $35.07^{\mathrm{c}} \pm 0.07$ & $11.88^{\mathrm{b}} \pm 0.03$ & $1.47^{\mathrm{a}} \pm 0.06$ & $1.78^{\mathrm{b}} \pm 0.06$ & $1.28^{\mathrm{a}} \pm 0.03$ \\
10 & $35.31^{\mathrm{b}} \pm 0.04$ & $11.74^{\mathrm{c}} \pm 0.01$ & $1.49^{\mathrm{a}} \pm 0.02$ & $1.83^{\mathrm{ab}} \pm 0.05$ & $1.28^{\mathrm{a}} \pm 0.01$ \\
15 & $35.55^{\mathrm{a}} \pm 0.13$ & $11.66^{\mathrm{c}} \pm 0.04$ & $1.53^{\mathrm{a}} \pm 0.03$ & $1.90^{\mathrm{a}} \pm 0.03$ & $1.27^{\mathrm{a}} \pm 0.03$ \\
\hline
\end{tabular}

Means with different letters on the same column are significantly different $(\mathrm{p} \leq 0.05)$.

Table 5. Bioactive composition of Jamun supplemented Indian chapatti.

\begin{tabular}{cccc}
\hline Supplementation (\%) & Anthocyanin (mg/100g) & $\begin{array}{c}\text { Total phenols } \\
\text { (mg GAE/100g) }\end{array}$ & Antioxidant activity (\%) \\
\hline Control & nd & $68.03^{\mathrm{d}} \pm 0.51$ & $56.59^{\mathrm{d}} \pm 0.55$ \\
5 & $1.41^{\mathrm{c}} \pm 0.10$ & $76.09^{\mathrm{c}} \pm 0.42$ & $68.80^{\mathrm{c}} \pm 0.56$ \\
10 & $2.30^{\mathrm{b}} \pm 0.07$ & $91.67^{\mathrm{b}} \pm 0.38$ & $74.98^{\mathrm{b}} \pm 0.64$ \\
15 & $2.64^{\mathrm{a}} \pm 0.07$ & $135.88^{\mathrm{a}} \pm 0.61$ & $81.71^{\mathrm{a}} \pm 0.63$ \\
\hline
\end{tabular}

nd: not detected; means with different letters on the same column are significantly different $(\mathrm{p} \leq 0.05)$.

increasing supplementation level but had significant effect. Control chapattis had protein content of $11.98 \%$ and in supplemented chapattis it was $11.88,11.74$ and $11.66 \%$ at 5,10 and $15 \%$ level, respectively. Paucean and Man (2014) incorporated pumpkin pulp in wheat bread at concentrations of 15,30 and $50 \%$ reported decrease in protein content of wheat bread with increase in supplementation level of pumpkin pulp. Jamun pulp significantly $(p \leq 0.05)$ enhanced the fibre content of supplemented chapattis. Control chapatti was found to have $1.67 \%$ crude fibre which increased to $1.90 \%$ at 15 $\%$ supplementation level. There was non-significant ( $p>0.05$ ) effect of supplementation levels on ash and fat content of Jamun pulp supplemented chapattis. Kulkarni and Joshi (2013) replaced 2.5\% of refined wheat flour with pumpkin powder in the biscuit and reported higher crude fibre and ash content in the optimized product over control samples whereas fat content remained same in both the samples.

Bioactive composition: The bioactive profile of control and Jamun pulp supplemented chapattis is detailed in table 5. Anthocyanin content increased linearly from $1.41 \mathrm{mg} / 100 \mathrm{~g}$ at $5 \%$ to $2.64 \mathrm{mg} / 100 \mathrm{~g}$ at $15 \%$ level. Similar trend was found for total phenolics that were found to be highest in 15\% Jamun pulp supplemented chapatti (135.88mg GAE/100g) and control chapatti had $68.03 \mathrm{mg}$ GAE $/ 100 \mathrm{~g}$ total phenols. The higher value of total phenols in supplemented chapattis compared to control chapatti may be due to addition of anthocyanins from Jamun pulp into chapattis. Estimation of antioxidant activity revealed that $15 \%$ Jamun supplemented chapatti had highest antioxidant activity (81.71\%) followed by $10 \%, 5 \%$ and control chapatti. A positive correlation coefficient ( $r=0.989, p<0.01)$ was observed between anthocyanins and antioxidant activity (Fig. 2) and also between total phenolic content and antioxidant activity $(\mathrm{r}=0.877, \mathrm{p}<0.01)$ (Fig. 3) that shows that phenolic compounds and anthocyanins might be the main components responsible for antioxidant activity of Jamun pulp supplemented chapattis. Jakobek et al. (2007) also found positive correlation of total phenolic content with antioxidant activities $(r=0.97, p<0.01)$ of red fruit juices rich in anthocyanins. Sonawane et al. (2013) reported that incorporation of 3\% Jamun powder in milk kulfi increased total phenolic content, anthocyanin and antioxidant activity (DPPH) by 78.68, 100 and $91.22 \%$, respectively. Thus, supplementation of Jamun powder in whole wheat flour showed value addition in the chapattis with respect to increased phenolic content and antioxidant activity.

\section{Conclusion}

Incorporation of Jamun (S. cumini L.) pulp in whole wheat flour enhanced anthocyanin, total phenolics and antioxidant activity of Indian chapatti with increasing supplementation level. Colour characteristics of chapatti 


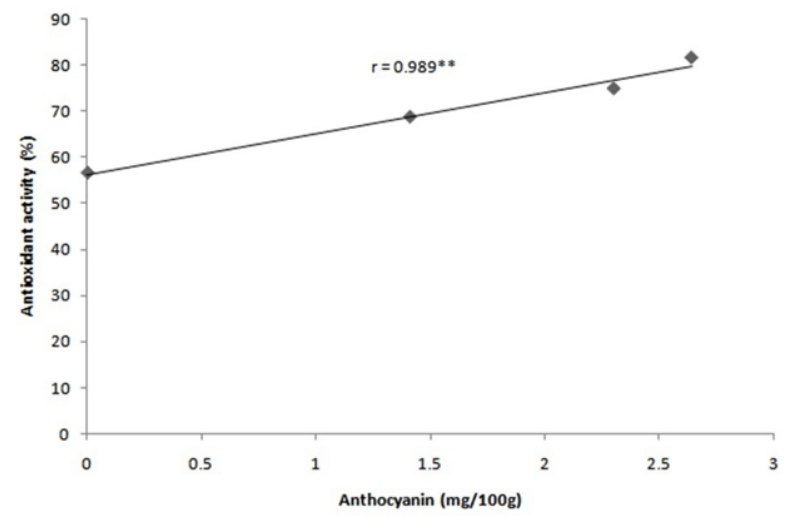

Fig. 2. Correlation plots between total anthocyanins and antioxidant activity of Jamun pulp supplemented chapattis. The correlation coefficients $(r)$ are marked in each plot; significant correlations are marked with asterik $(* *=$ significance at $p \leq 0.01)$.

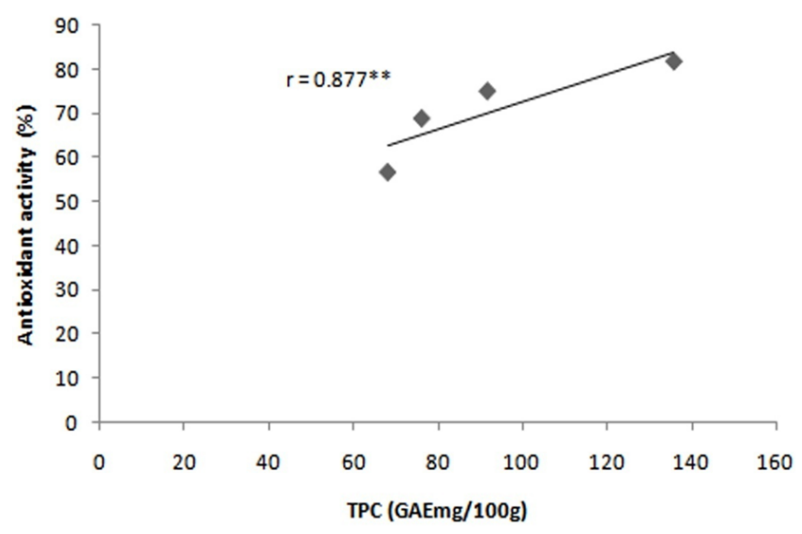

Fig. 3. Correlation plots between total phenolic content (TPC) and antioxidant activity of Jamun pulp supplemented chapattis. The correlation coefficients (r) are marked in each plot; significant correlations are marked with asterik $(* *=$ significance at $p \leq 0.01$ ).

were affected by increasing levels of supplementation. Jamun pulp in whole wheat flour help improved texture of chapattis. Moreover, fibre content also increased in supplemented chapattis with increasing levels. The sensory attributes showed that 5, 10 and 15\% Jamun pulp supplemented chapattis were acceptable, however, $10 \%$ received highest overall acceptability scores. Thus, potential use of Jamun pulp in whole wheat flour can be successfully done to improve functional and bioactive properties of the chapattis. The future possibilities can be to combine antioxidant rich fruits with cereal products in order to achieve well balanced antioxidant rich foods.

\section{ACKNOWLEDGMENTS}

Ministry of Science and Technology (Department of Science and Technology), Government of India, New Delhi is acknowledged for rendering the financial support under INSPIRE (DST/INSPIRE Fellowship/2012, 292) Programme to carry out the present work.

\section{REFERENCES}

AACC (2000). Approved Methods. American Association of Cereal Chemist, $10^{\text {th }}$ ed. AACC, St. Paul Minnesota, USA.

Ali, S., Masud, T., Abbasi, K.S., Ali, A. and Hussain, A. (2013). Some compositional and biochemical attributes of jaman fruit (Syzygium cumini L.) from Potowar region of Pakistan. Res. Pharm., 3: 1-9.

AOAC (2000). Official Methods of Analysis, Association of Official Analytical Chemists, Gaithersburg, Maryland, USA.

Austin, A. and Ram, A. (1971). Studies on chapatti making quality of wheat: Tech Bull 31. Indian Council of Agricultural Research, New Delhi, pp 108.

Brand-Williams, W., Cuvelier, M.E. and Berset, C. (1995). Use of a free radical method to evaluate antioxidant activity. LWT-Food Sci.Technol., 28: 25-30.

Camire, M.E., Dougherty, M.P. and Briggs, J.L. (2007). Functionality of fruit powders in extruded corn breakfast cereals. Food Chem., 101: 765-770.

Chattopadhyay, P., Chatterjee, S. and Sen, S.K. (2008). Biotechnological potentials of natural food grade colourants. Afr. J. Biotechnol., 7: 2972-2985.

Chen, J.Y., Piva, M. and Labuza, T.P. (1984). Evaluation of water binding capacity (WBC) of food fibre sources. $J$. Food Sci., 49: 59-63.

Chowdhury, P. and Ray, R.C. (2007). Fermentation of Jamun (Syzgium cumini L.) fruits to form red wine. ASEAN Food J., 14: 15-23.

Cliff, M.A., King, M.C. and Schlosser, J. (2007). Anthocyanin, phenolic composition, colour measurement and sensory analysis of $\mathrm{BC}$ commercial red wines. Food Res. Int., 40: $92-100$.

D’Mello, P.M., Jadhav, M.A. and Jolly, C.I. (2000). Free radical scavenging activity of Syzygium cumini and ficus bengalensis- Plants used in Ayurveda for diabetes mellitus. Indian Drugs, 37: 518-520.

Dar, B.N., Sharma, S., Singh, B. and Kaur, G. (2014). Quality assessment and Physico-chemical characteristics of bran enriched chapattis. Int. J. Food Sci., 2014: 1-6.

Francis, D. and Phelps, S.K. (2003). Fruit and Vegetable juice powders add value to cereal products. Cereal Foods World, 48: 244-246.

Gao, L., Wang, S., Oomah, B.D. and Mazza, G. (2002). Antioxidant activity of wheat millstreams. Wheat quality elucidation, St. Paul, MN: AACC International.

Hutchings, J.B. (1999). Food Color and Appearance, Springer, Windsor, CT.

Jakobek, L., Seruga, M., Medvidovic-Kosanovic, M. and Novak, I. (2007). Anthocyanin content and antioxidant activities of various red fruit juices. Dtsch. Lebensm. Rundsch., 103: 58-64.

Joshi, V.K., Sharma, R., Girdher, A. and Abrol, G.S. (2012). Effect of dilution and maturation on physico-chemical and sensory quality of Jamun (Black plum) wine. Indian J. Nat. Prod. Resour., 3: 222-227.

Kadam, M.L., Salve, R.V., Mehrajfatema, Z.M. and More, S.G. (2012). Development and evaluation of composite flour for missi roti /chapatti. J. Food Process. Technol., 3: $1-7$.

Kopjar, M., Pilizota, V., Subaric, D. and Babic, J. (2009). Prevention of thermal degradation of red currant juice anthocyanins by phenolic compounds addition. Croat. 
J. Food Sci. Technol., 1: 24-30.

Kulkarni, A.S. and Joshi, D.C. (2013). Effect of replacement of wheat flour with pumpkin powder on textural and sensory qualities of biscuit. Int. Food Res. J., 20: 587-591.

Larmond, E. (1970). Methods of Sensory Evaluation of Food, $2^{\text {nd }}$ Ed. Food Research Institute, Canada Department of Agriculture, Ottawa.

Paucean, A. and Man, S. (2014). Physico-chemical and sensory evaluation of wheat bread with pumpkin (Cucurbita maxima) pulp incorporated. J. Agroaliment. Proc. Technol., 20: $26-32$.

Ranganna, S. (1997). Handbook of analysis and quality control for fruit and vegetable products, $2^{\text {nd }}$ Ed. Tata McGraw Hills Publ Co. Ltd. New Delhi.

Sagrawat, H., Mann, A. and Kharya, M. (2006). Pharmacological Potential of Eugenia Jambolana: A Review. Pharmaco-genesis Magazice, 2: 96-104.
Shahnawaz, M., Sheikh, S.A. and Nizamani, S.M. (2009). Determination of Nutritive Values of Jamun Fruit (Eugenia jambolana) Products. Pak. J. Nutr., 8: 1275 -1280 .

Sharma, S., Mehta, B.K., Mehta, D., Nagar, H. and Mishra, A. (2012). A review on pharmacological activity of Syzygium cumini extracts using different solvent and their effective doses. Int. Res. J. Pharm., 3: 54-58.

Sidhu, J.S., Seibel, W. and Brummer, J.M. (1988). Measurement of Chapatti texture using wick universal testing machine. Food Sci. Technol., 21: 147-152.

Sonawane, S.K., Arya, S.S. and Gaikwad, S. (2013). Use of jambhul powder in the development of bioactive components enriched milk kulfi. J. Microbiol. Biotechnol. Food Sci., 2: 2440-2443. 